\title{
Optimum pulse duration and radiant exposure for vascular laser therapy of dark port-wine skin: a theoretical study
}

\author{
James W. Tunnell, Lihong V. Wang, and Bahman Anvari
}

\begin{abstract}
Laser therapy for cutaneous hypervascular malformations such as port-wine stain birthmarks is currently not feasible for dark-skinned individuals. We study the effects of pulse duration, radiant exposure, and cryogen spray cooling (CSC) on the thermal response of skin, using a Monte Carlo based optical-thermal model. Thermal injury to the epidermis decreases with increasing pulse duration during irradiation at a constant radiant exposure; however, maintaining vascular injury requires that the radiant exposure also increase. At short pulse durations, only a minimal increase in radiant exposure is necessary for a therapeutic effect to be achieved because thermal diffusion from the vessels is minimal. However, at longer pulse durations the radiant exposure must be greatly increased. There exists an optimum pulse duration at which minimal damage to the epidermis and significant injury within the targeted vasculature occur. For example, the model predicts optimum pulse durations of approximately $1.5,6$, and $20 \mathrm{~ms}$ for vessel diameters of 40,80 , and $120 \mu \mathrm{m}$, respectively. Optimization of laser pulse duration and radiant exposure in combination with CSC may offer a means to treat cutaneous lesions in dark-skinned individuals. (c) 2003 Optical Society of America

OCIS codes: $170.0170,170.1610,170.1870,170.3660$.
\end{abstract}

\section{Introduction}

Laser treatments of cutaneous hypervascular malformations such as port-wine stain birthmarks, telangiectasia, and facial veins are based on the theory of selective photothermolysis. ${ }^{1}$ Light, preferentially absorbed by hemoglobin within the ectatic dermal blood vessels, is converted to thermal energy. Ideally, by choice of an appropriately short laser pulse, thermal energy remains confined to the targeted vasculature, selectively inducing irreversible injury.

However, melanin, a competing chromophore that exists primarily within the overlying epidermis, absorbs incident light directly. Absorption of light by melanin results in nonselective heating of the epidermis, which can clinically result in dyspigmentation, crusting, and blistering. ${ }^{2-4}$ Dark-skinned patients are at particular risk of these complications because of the high melanin content of their skins. ${ }^{2,5}$ There-

J. W. Tunnell and B. Anvari (anvari@rice.edu) are with the Department of Bioengineering, MS142, Rice University, P.O. Box 1892, Houston, Texas. L. V. Wang is with the Department of Biomedical Engineering, Texas A\&M University, 3120 TAMU, College Station, Texas 77843-3120.

Received 22 July 2002; revised manuscript received 12 November 2002 .

0003-6935/03/071367-12\$15.00/0

(C) 2003 Optical Society of America fore, epidermal injury currently places a limit on the maximum radiant exposure that can be used in therapy.

Cryogen spray cooling (CSC) is currently used to protect the epidermis during laser therapy. ${ }^{6-9}$ In this method, a short cryogenic spurt (of the order of tens of milliseconds) is delivered to the skin's surface immediately before the onset of the laser pulse. Appropriate timing of the spurt's duration ensures a selective cooling effect (i.e., only the superficial epidermis is cooled and not the deeper dermis); however, little is known about the optimum cooling time for epidermal protection. Several recent theoretical and experimental studies have suggested that longer cryogen spurt durations (200-300 ms) than those used in current clinical practice $(\sim 60 \mathrm{~ms})$ may provide more epidermal protection ${ }^{5,10}$ without compromising cooling selectivity. ${ }^{11}$

Although CSC has been shown to raise the epidermal damage thresholds in lightly to moderately pigmented skin, 5,7,10 it has not been shown to be effective in protecting the epidermis in dark-skinned individuals. $^{5}$ Many mathematical models ${ }^{12-21}$ have been developed for the study of laser therapy in human skin; however, with the exception of a few, ${ }^{12,21}$ all models represent the epidermis as a homogeneously absorbing medium, which is not consistent with epidermal anatomy. Proper representation of the epidermal anat- 
omy is important for predicting rises in epidermal temperature in the presence of thermal diffusion. ${ }^{12}$

In this study we develop a mathematical model with which to investigate epidermal injury during pulsed laser irradiation in conjunction with CSC. This model incorporates two unique features that represent the physics of the problem. First, we represent optical absorption by melanin consistent with the morphology of melanin concentration and distribution. Second, we represent the thermal boundary condition induced by CSC as a time-varying heat flux that accounts for the dynamic cooling process.

Using this model, we investigate the role of pulse duration, radiant exposure, and CSC in epidermal injury. We address two key issues: the use of CSC to increase epidermal damage thresholds and the role of pulse duration in combination with CSC in epidermal injury.

First, we investigate the ability of CSC to increase the threshold for epidermal damage as a function of skin pigmentation level. Several recent experimental studies ${ }^{5,10}$ have shown that CSC can increase the epidermal damage threshold by approximately a factor of 2-3, allowing for the safe use of higher radiant exposures. These higher radiant exposures used without CSC resulted in thermally induced damage to the epidermis and perivascular tissues, thus decreasing the selectivity of vascular damage; however, the use of long cryogen spurts $(>200 \mathrm{~ms})$ protected not only the epidermis but also the perivascular tissue. In addition, higher radiant exposures used in conjunction with CSC increased the depth of vascular injury within the dermis. A mathematical model of increased radiant exposures will help to explain the tissue damage phenomena that were observed in experimental studies.

Second, we investigate how the laser pulse duration in combination with CSC affects epidermal injury. Proper anatomical representation of epidermal melanin distribution allows for moreaccurate calculation of epidermal temperatures in response to various laser pulse durations. In addition, it has been shown ${ }^{22}$ that CSC deposits a pool of cryogen that resides on the skin surface well after the end of cryogen spurt. Thus additional cooling is provided to the skin during and after the laser pulse. We show that the combination of optimum pulse duration in conjunction with CSC may provide a method for protecting the epidermis in darkskinned individuals during pulsed laser irradiation.

\section{Materials and Methods}

Figure 1 illustrates the three main components of the mathematical model: a Monte Carlo lightdistribution model, a finite-difference solution to the heat-conduction equation, and an Arrhenius rate process integral to quantify thermal damage. Each of these components is described in detail in a following subsection.

Given the optical properties of the tissue and the geometry of the problem, we first calculate the light distribution and the rate of energy absorption per unit

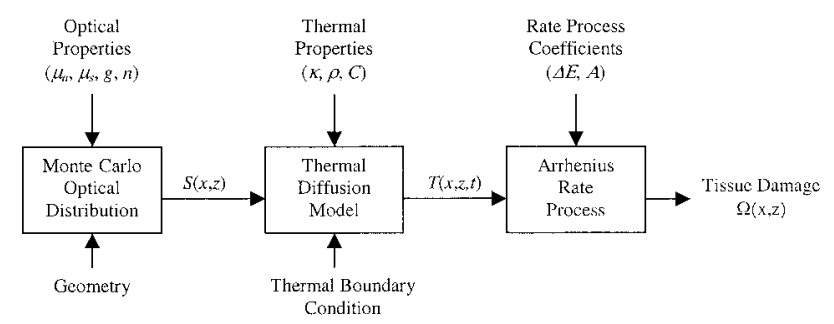

Fig. 1. Block diagram of the components in the mathematical model.

skin volume, $S(x, z)\left[\mathrm{W} / \mathrm{m}^{3}\right]$, where $x$ and $z$ are the lateral and the depth dimensions, respectively. This term is subsequently used as the heat-generation source term in the thermal diffusion model. The optical properties of the tissue include absorption coefficient $\mu_{a}[1 / \mathrm{m}]$, scattering coefficient $\mu_{s}[1 / \mathrm{m}]$, anisotropy factor $g$, and refractive index $n$.

The thermal diffusion model incorporates the thermal boundary condition induced by CSC, heat generated by laser irradiation, and the thermal properties of the tissue, resulting in temperature history $T(x, z$, $t)\left[{ }^{\circ} \mathrm{C}\right]$ within the tissue, where $t$ is the time $[\mathrm{s}]$. The thermal properties consist of density $\rho\left[\mathrm{kg} / \mathrm{m}^{3}\right]$, specific heat capacity $C\left(\mathrm{~J} / \mathrm{kg}{ }^{\circ} \mathrm{C}\right)$, and thermal conductivity $\kappa\left(\mathrm{W} / \mathrm{m}{ }^{\circ} \mathrm{C}\right)$. Inasmuch the degree of tissue damage depends on the exposure temperature and time, we use the Arrhenius rate process integral to quantify the damage profile, $\Omega(x, z) .{ }^{23}$ The rate process coefficients for the Arrhenius damage integral include the frequency factor $A(1 / \mathrm{s})$ and the activation energy $\Delta E[\mathrm{~J} / \mathrm{mol}]$.

We used a semi-infinite two-dimensional geometry (Fig. 2) consisting of a $60-\mu \mathrm{m}$-thick epidermis overlying a semi-infinite dermis. A $10-\mu \mathrm{m}$-thick melanin-filled layer was inserted along the bottom of the epidermis to simulate the epidermal basal layer at the dermo-epidermal junction. Nonoverlapping blood vessels were randomly distributed within the dermis. Four vessel diameters $[d=40,80,120,400$ $\mu \mathrm{m}$; Figs. 2(a), 2(b), 2(c), and 2(d), respectively] were investigated at blood volume fractions $\left(p_{\mathrm{bl}}\right)$ of $3.2 \%$, $6 \%, 8 \%$, and $10 \%$, respectively, consistent with the morphology of cutaneous hypervascular lesions. ${ }^{24,25}$

\section{A. Light-Distribution Model}

The Monte Carlo light-distribution model used in this study was developed by Wang et al. The details will not be repeated here but can be found in Ref. 26-28. This light-distribution model simulates photon paths within tissues that contain multiply embedded objects of different optical properties. The deltascattering technique was used for photon tracing 29 to simplify the algorithm greatly because it allows a photon packet to be traced without directly dealing with photon crossings at interfaces between different tissue types. This technique can be used only for refractive-index-matched tissues, although it allows the ambient clear medium (e.g., air) and the tissue to have mismatched refractive indices. Because soft 


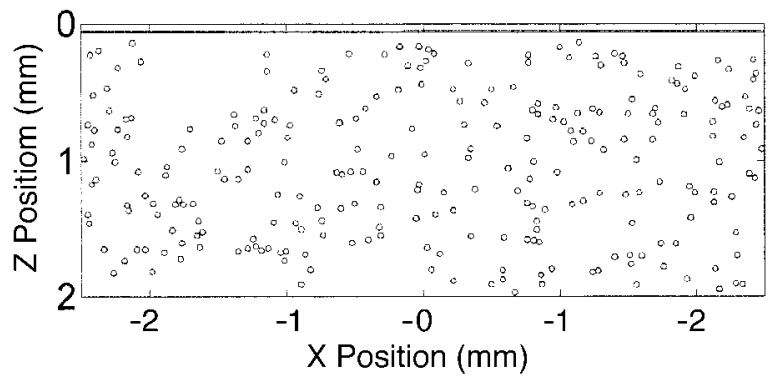

(a)

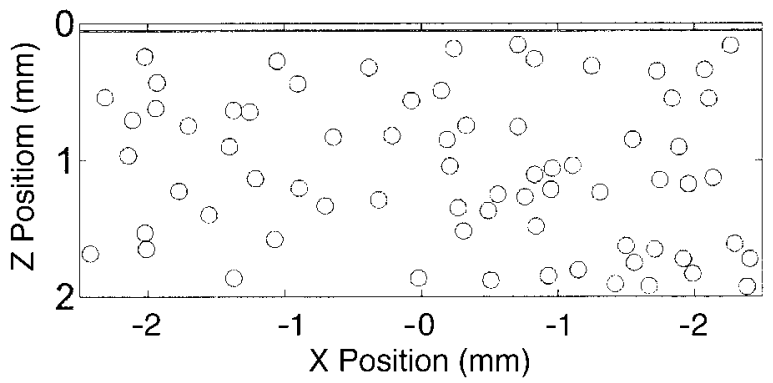

(c)

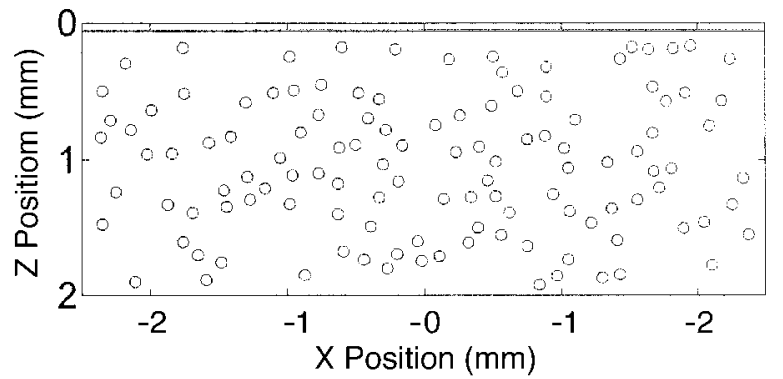

(b)

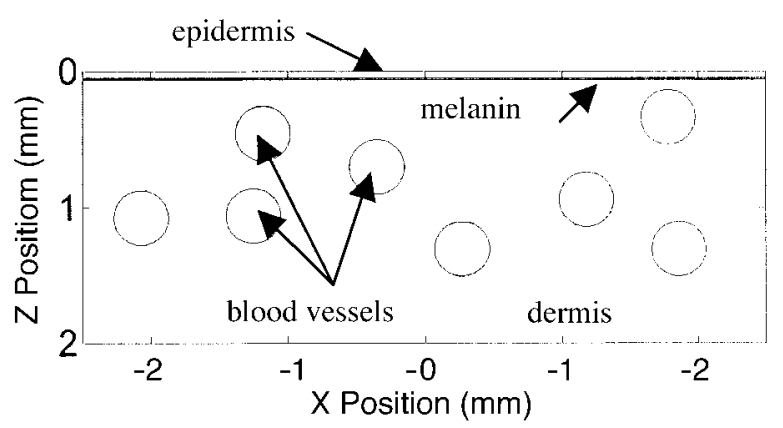

(d)

Fig. 2. Geometries used in this study. A $10-\mu \mathrm{m}$-thick basal layer was located $60 \mu \mathrm{m}$ below the skin surface. Four vessel diameters $[d=$ $40,80,120,400 \mu \mathrm{m}$; (a), (b), (c), and (d) respectively] at their respective blood volume fractions $\left(p_{\mathrm{bl}}\right)$ of $3.2 \%, 6 \%$, $8 \%$, and $10 \%$ were investigated.

tissues have similar indices of refraction, this limitation does not pose a problem in our simulations.

The optical simulation was used to calculate the power deposition $S\left[\mathrm{~W} / \mathrm{m}^{3}\right]$ for the geometries shown in Fig. 2. Each simulation was carried out for $1,000,000$ photons. We simulated an incident beam of 6-mm diameter at $585 \mathrm{~nm}$, a commonly used wavelength for laser treatment of vascular lesions. The optical properties for each skin component ${ }^{30}$ are listed in Table 1. The optical absorption coefficient for the melanin-filled epidermal layer $\left(\mu_{a}{ }^{\text {mel-epi }}\right)$ was determined as a function of the volume fraction of epidermal melanin, $p_{\text {mel }}$ :

$$
\mu_{a}^{\text {mel-epi }}\left(p_{\text {mel }}\right)=\frac{\left[p_{\text {mel }} \mu_{a}^{\text {mel }}+\left(100-p_{\text {mel }}\right) \mu_{a}{ }^{\text {epi }}\right]}{100}
$$

where $\mu_{a}{ }^{\text {epi }}$ is the melanin-absent optical absorption coefficient of the epidermis. Several studies that have been reported in the literature measured the melanin content for various skin types and suggest that $p_{\text {mel }}$ ranges from approximately $3 \%$ for light skin

Table 1. Optical Properties of Various Skin Components Used in Our Monte Carlo Model ${ }^{\alpha}$

\begin{tabular}{cccc}
\hline Skin Component & $\mu_{a}(1 / \mathrm{cm})$ & $\mu_{s}(1 / \mathrm{cm})$ & $g$ \\
\hline Epidermis & 2.4 & 470 & 0.79 \\
Melanin & 350 & 470 & 0.79 \\
Dermis & 2.4 & 129 & 0.79 \\
Blood & 191 & 467 & 0.99 \\
\hline
\end{tabular}

${ }^{a}$ Source: Ref. 30 . to $50 \%$ for dark skin. ${ }^{31-35}$ We represent light, moderately pigmented, and dark skin by using the values $p_{\text {mel }}=5,25,50 \%$, respectively.

\section{B. Heat-Transfer Model}

We used the explicit central finite-difference technique $^{36}$ to solve the two-dimensional transient form of the heat-conduction equation

$$
\kappa \nabla^{2} T(x, z, t)+S(x, z)=\rho C \frac{\partial T(x, z, t)}{\partial t} .
$$

We neglected heat transfer owing to blood perfusion because those effects are not important on the short time scales (i.e., hundreds of milliseconds) used in this study. ${ }^{37}$ Adiabatic boundary conditions were applied at $z=\infty$ and $x= \pm \infty$. A constant initial temperature of $33{ }^{\circ} \mathrm{C}$ was used for the entire tissue volume. The thermal properties of $\operatorname{skin}^{38}$ used in this study are $\rho=1200 \mathrm{~kg} / \mathrm{m}^{3} ; C=3600 \mathrm{~J} / \mathrm{kg}^{\circ} \mathrm{C}$; and $\kappa=0.26,0.53,0.53 \mathrm{~W} / \mathrm{m}{ }^{\circ} \mathrm{C}$ for epidermis, dermis, and blood, respectively. The heat-source term, $S$, was present only during the time of laser pulse duration, $t_{p}$.

The time-varying thermal boundary condition was modeled in three temporal intervals consistent with previous reports of CSC applied to skin. ${ }^{39-42}$ This surface heat flux $(q)$ is represented as

$$
q_{i}=\left.h_{i}\left[T_{i}-T(t)\right]\right|_{z=0},
$$

where $h_{i}$ is the heat-transfer coefficient $\left(\mathrm{W} / \mathrm{m}^{2}{ }^{\circ} \mathrm{C}\right)$ and $T_{i}$ is the cryogen film's temperature during 
Table 2. Surface Thermal Boundary Condition Parameters

\begin{tabular}{lccr}
\hline \multicolumn{1}{c}{ Time Interval $(i)$} & $\begin{array}{c}h_{i} \\
\left(\mathrm{~W} / \mathrm{m}^{2}{ }^{\circ} \mathrm{C}\right)\end{array}$ & $\begin{array}{c}T_{i} \\
\left({ }^{\circ} \mathrm{C}\right)\end{array}$ & $\begin{array}{c}\text { Duration } \\
(\mathrm{ms})\end{array}$ \\
\hline For spurt application & 4000 & -50 & $0-300$ \\
For cryogen pool residence & 3000 & -26 & 200 \\
For rewarming & 10 & 25 & $>500$ \\
\hline
\end{tabular}

time interval $i$. Table 2 lists $h_{i}, T_{i}$, and the duration of the three time intervals used in this study.

\section{Arrhenius Damage Integral}

The Arrhenius rate process integral was used to quantify thermal damage:

$$
\begin{aligned}
\Omega(x, z, \tau) & =\ln \left[\frac{C(x, z, 0)}{C(x, z, \tau)}\right] \\
& =A \int_{0}^{\tau}\left\{\exp \left[-\frac{\Delta E}{R T(x, z, t)}\right] \mathrm{d} t\right\},
\end{aligned}
$$

where $C$ is the remaining concentration of native state tissue at exposure time $\tau(s)$ and $R$ is the universal gas constant $(8.314 \mathrm{~J} / \mathrm{mol} \mathrm{K})$. We used the values $A=1.8 \times 10^{51} 1 / \mathrm{s}$ and $\Delta E=327,000 \mathrm{~J} / \mathrm{mol}$ for bulk skin as reported in the literature. ${ }^{43}$ Calculations of $\Omega$ were carried out for a period of time until thermal damage accumulation had ceased. We can approximate threshold temperature for tissue injury, $T_{\text {th }}$, by assuming that the exposure time is equal to the laser pulse duration and that the damage end point occurs when $\Omega(x, z, t)=1$ (i.e., that $63 \%$ of the tissue in that volume has been coagulated). Rearranging Eq. (4) gives

$$
T_{\text {th }}=\frac{\Delta E}{R\left[\ln \left(t_{p}\right)-\ln \left(\frac{1}{A}\right)\right]} .
$$

\section{Results}

\section{A. Epidermal Damage Threshold $\left(D_{\mathrm{th}}\right)$}

We define the epidermal damage threshold $\left(D_{\text {th }}\right)$ as the minimum radiant exposure that causes irreversible thermal injury to the epidermis. Thermal injury to the epidermis depends on both the exposure time and temperature [following Eq. (4)]. We can approximate $D_{\text {th }}$ by determining the radiant exposure that results in a maximum temperature of $T_{\text {th }}$ within the epidermis for a given cooling regime. Using Eq. (5) and $t_{p}=1.5 \mathrm{~ms}$ yields $T_{\text {th }}=83^{\circ} \mathrm{C}$. Note that use of CSC should increase $D_{\text {th }}$ as a result of temperature reduction within the epidermis before laser exposure.

Figure 3 shows $D_{\text {th }}$ versus $t_{\mathrm{CSC}}$ for three levels of epidermal pigmentation that represent light skin $\left(p_{\text {mel }}=5 \%\right)$, moderately pigmented skin $\left(p_{\text {mel }}=\right.$ $25 \%)$, and dark skin $\left(p_{\text {mel }}=50 \%\right)$. Values of $D_{\text {th }}$ for each pigmentation level increase rapidly for $t_{\mathrm{CSC}}<$ $100 \mathrm{~ms}$, whereas the rate of increase in $D_{\text {th }}$ declines

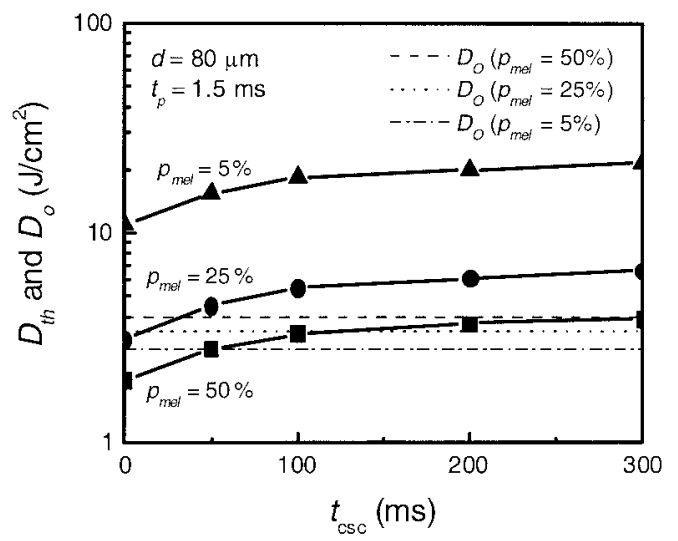

Fig. 3. Threshold radiant exposure $D_{\text {th }}$ for epidermal damage versus duration of the cryogen spurt $t_{\mathrm{CSC}}$ for lightly pigmented $\left(p_{\text {mel }}=5 \%\right)$, moderately pigmented $\left(p_{\text {mel }}=25 \%\right)$, and dark $\left(p_{\text {mel }}=\right.$ $50 \%)$ skin $\left(t_{p}=1.5 \mathrm{~ms}, d=80 \mu \mathrm{m}\right)$. Also plotted are values of therapeutic radiant exposure $D_{o}$, defined as the value necessary to induce a temperature of $120^{\circ} \mathrm{C}$ within the most superficial blood vessels.

for $t_{\mathrm{CSC}}>100 \mathrm{~ms}$. The values for $D_{\mathrm{th}}$ increase with decreasing pigmentation.

We define the therapeutic radiant exposure, $D_{o}$, as the value necessary to induce a maximum temperature of $120^{\circ} \mathrm{C}$ within the most superficial blood vessels (e.g., in Fig. 2, those blood vessels closest to $z=$ $0)$. This temperature represents the upper limit at which a therapeutic effect can be generated and hightemperature ablation processes avoided. ${ }^{23}$ At the time scales used in this study, we expect these temperatures to generate water-dominated processes such as intracellular and extracellular vacuole formation, ${ }^{23}$ which are typical damage phenomena seen in pulsed laser irradiation of skin. ${ }^{5,10}$ Calculated values of $D_{o}$ are shown for $d=80 \mu \mathrm{m}$ and $t_{p}=1.5 \mathrm{~ms}$ for each pigmentation level.

Figure 4 shows temperature versus depth (with the $x$ direction coming out of the page) at $D_{\text {th }}, p_{\text {mel }}=25 \%$, $d=80 \mu \mathrm{m}$, and $t_{p}=1.5 \mathrm{~ms}$, without and with $t_{\mathrm{CSC}}=$ $300 \mathrm{~ms}$. Three time points are shown: immediately, 5, and 10, ms after the laser pulse. Sharp temperature spikes caused by epidermal melanin heating near the skin surface are present in Figs. 4(a) and 4(b). In Fig. 4(b) the temperature spike was just below $T_{\text {th }}\left(83^{\circ} \mathrm{C}\right)$, whereas without cooling [Fig. 4(a)] it was well above this threshold value. At $5 \mathrm{~ms}$ following the laser pulse, the epidermal temperature spike decreased dramatically both with and without cooling [Figs. 4(c) and 4(d), respectively].

We present damage maps to illustrate the outcome of using CSC with higher radiant exposures. These maps show cross-sectional views of skin in which white areas represent the native healthy tissue and shaded areas represent coagulated tissue $(\Omega>1)$. Figure 5 shows damage maps within irradiated skin for four cases: (a) no CSC and $D_{\text {th }}\left(=3.1 \mathrm{~J} / \mathrm{cm}^{2}\right)$, (b) $50-\mathrm{ms} \mathrm{CSC}$ and $D_{\text {th }}\left(=4.5 \mathrm{~J} / \mathrm{cm}^{2}\right)$, (c) $300-\mathrm{ms} \mathrm{CSC}$ and $D_{\text {th }}\left(=6.6 \mathrm{~J} / \mathrm{cm}^{2}\right)$, and (d) no CSC with $D=6.6 \mathrm{~J} / \mathrm{cm}^{2}$ [i.e., case (c) without CSC]. The depth of damaged 


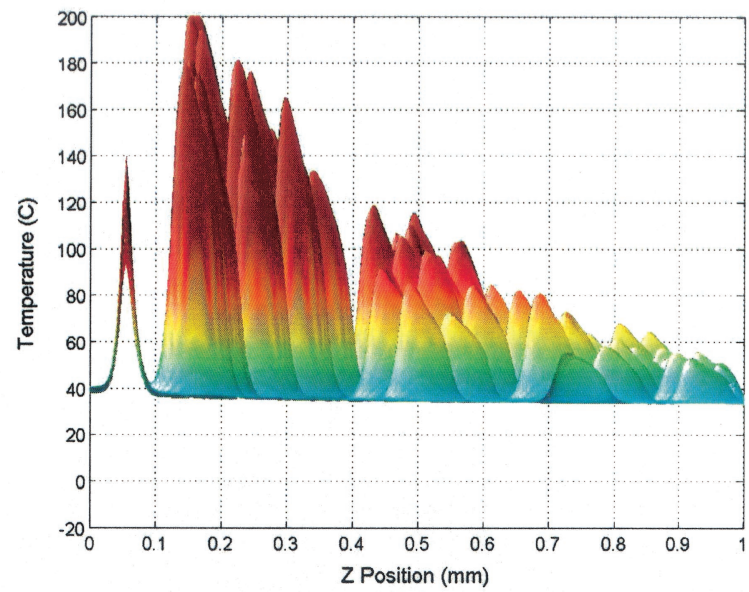

(a)

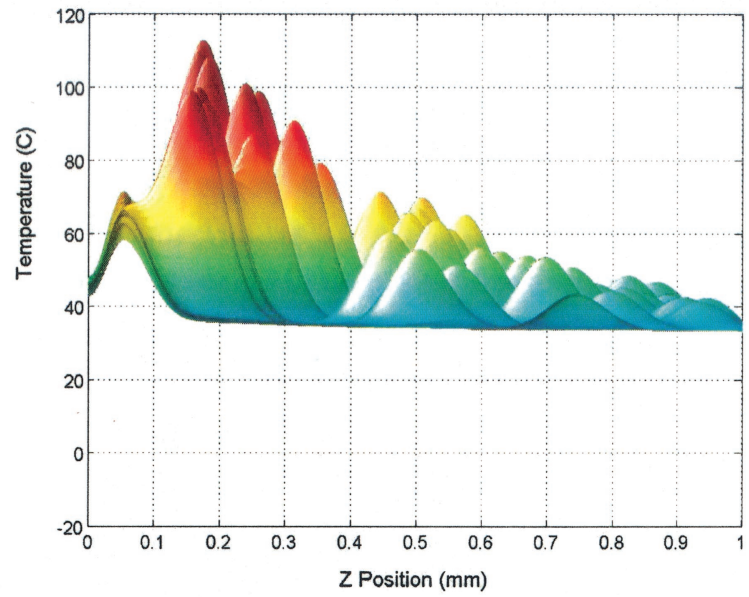

(c)

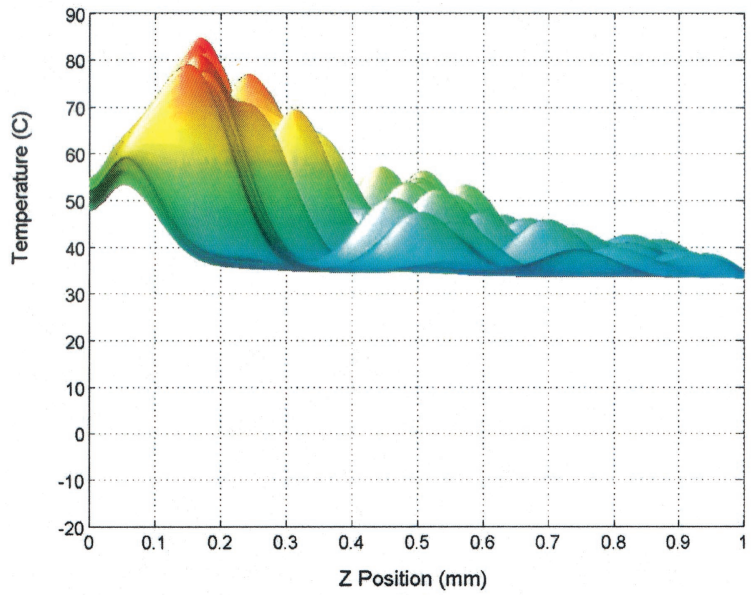

(e)

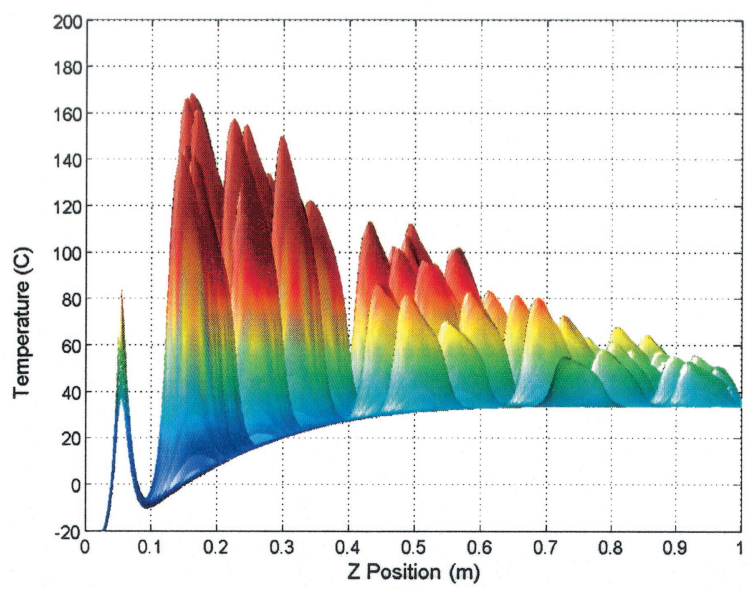

(b)

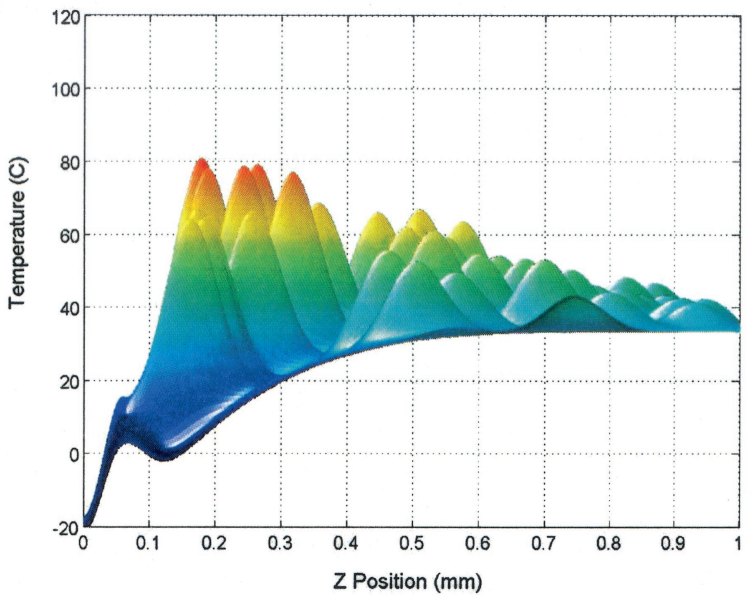

(d)

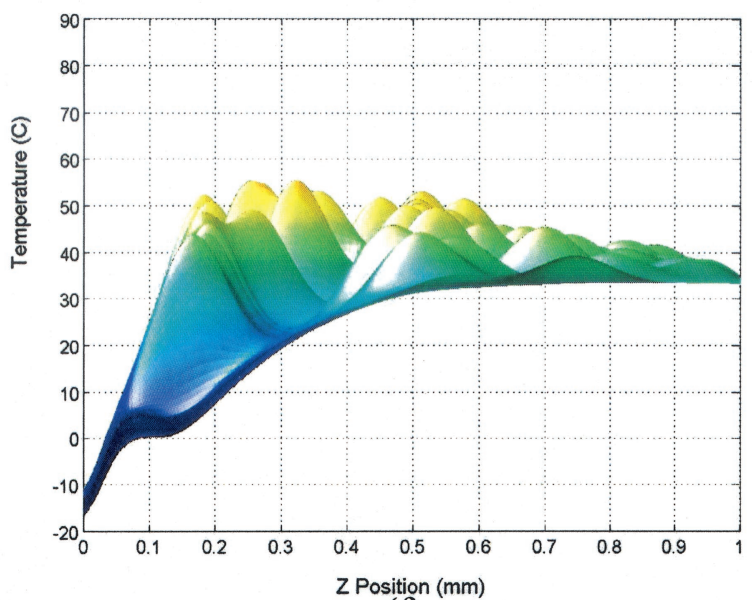

(f)

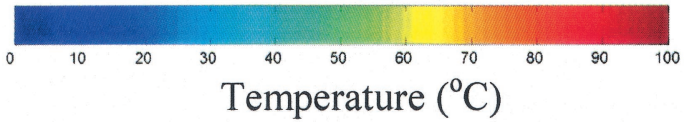

Fig. 4. Three-dimensional plots of the temperature, with the $x$ direction coming out of the page, for a 1.5-ms laser pulse without [(a), (c), (e)] and with [(b), (d), (f)] $t_{\mathrm{CSC}}=300 \mathrm{~ms}$. Temperature profiles are shown immediately [(a) and (b)], $5 \mathrm{~ms}[(\mathrm{c})$ and (d)], and $10 \mathrm{~ms}[(\mathrm{e})$ and (f)] following the laser pulse. 


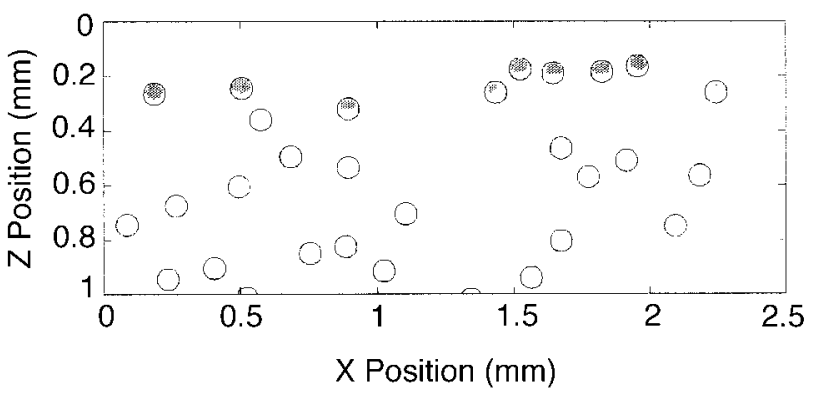

(a)

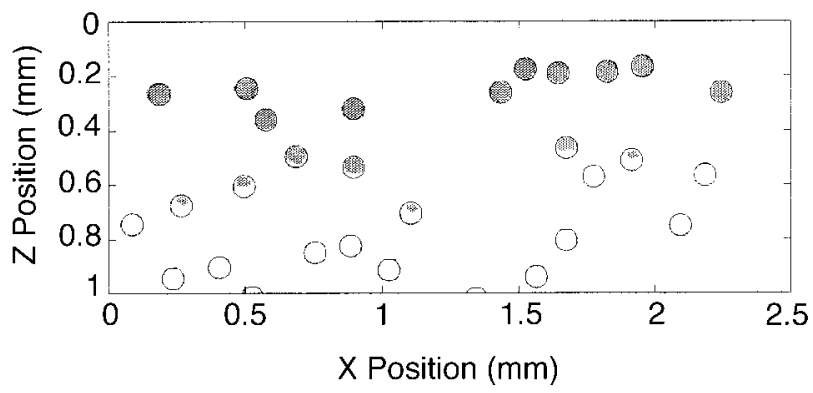

(c)

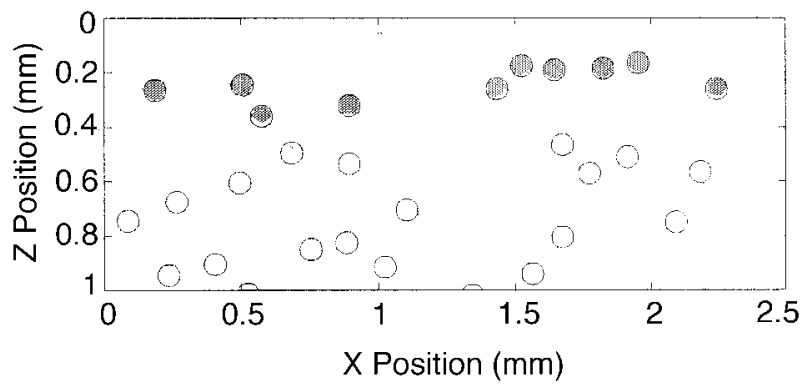

(b)

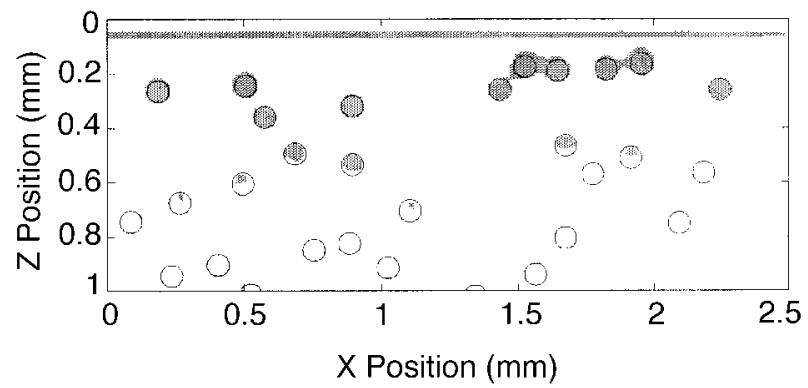

(d)

Fig. 5. Damage profile maps in skin for $d=80 \mu \mathrm{m}, t_{p}=1.5 \mathrm{~ms}$, and $p_{\text {mel }}=25 \%$ : (a) no CSC and $D_{\text {th }}\left(=3.1 \mathrm{~J} / \mathrm{cm}^{2}\right)$, (b) $50 \mathrm{~ms} \mathrm{CSC} \mathrm{and}$ $D_{\text {th }}\left(=4.5 \mathrm{~J} / \mathrm{cm}^{2}\right)$, (c) $300 \mathrm{~ms} \mathrm{CSC}$ and $D_{\text {th }}\left(=6.6 \mathrm{~J} / \mathrm{cm}^{2}\right)$, and (d) no CSC with $D=6.6 \mathrm{~J} / \mathrm{cm}^{2}$ [i.e. case (c) without CSC].

blood vessels and the extent of damage within each individual vessel increased with radiant exposure. For high radiant exposure without the use of CSC [case (d)], we observed extensive epidermal injury in addition to perivascular damage. The latter type of damage, when it is observed in conjunction with vessels in close proximity to one another, is interconnected among multiple vessels. However, for cooling with high radiant exposure [case (c)], CSC protected the epidermis and eliminated damage to perivascular tissue.

\section{B. Therapeutic Radiant Exposure $\left(D_{0}\right)$ and Pulse Duration}

The therapeutic radiant exposure depends on both the size of the targeted vessel and the laser pulse duration. For $d=120 \mu \mathrm{m}$ and $t_{p}=0.5 \mathrm{~ms}$, a radiant exposure of $3.6 \mathrm{~J} / \mathrm{cm}^{2}$ is required for raising the peak temperature of the blood to $120^{\circ} \mathrm{C}$. With increased pulse duration, the blood temperature decreases owing to heat conduction away from the vessel. Figure 6 shows the peak temperature, $T_{\text {peak }}$, within the blood vessel and the epidermis for a constant radiant exposure and various laser pulse durations. Increasing the pulse duration while maintaining a constant radiant exposure decreases the temperature within the epidermis; however, the temperature within the blood vessel also decreases.

Figure 7 illustrates $D_{o}$ versus pulse duration for several vessel sizes. For each vessel size the slope of $D_{o}$ versus $t_{p}$ changes from relatively flat at shorter pulse durations to much steeper at longer pulse durations. The slope transition occurs at pulse dura- tions $t_{p}{ }^{\prime} \cong 1.5,6,20,50 \mathrm{~ms}$ for blood vessel diameters of $40,80,120$, and $400 \mu \mathrm{m}$, respectively.

\section{Epidermal Injury and Pulse Duration}

Increased pulse durations can decrease the epidermal temperature even when a therapeutic temperature is maintained within the blood. Figure 8 shows the peak temperature within the epidermis while the skin is irradiated at $D_{o}$ for each combination of pulse duration and vessel size (i.e. values of $D_{o}$ at $t_{p}$ given in Fig. 7 for each vessel size). We notice that the epidermal $T_{\text {peak }}$ initially decreases with $t_{p}$ and reaches a minimum. We define the pulse duration at which this minimum occurs as the optimum pulse duration. This value corresponds to that at which

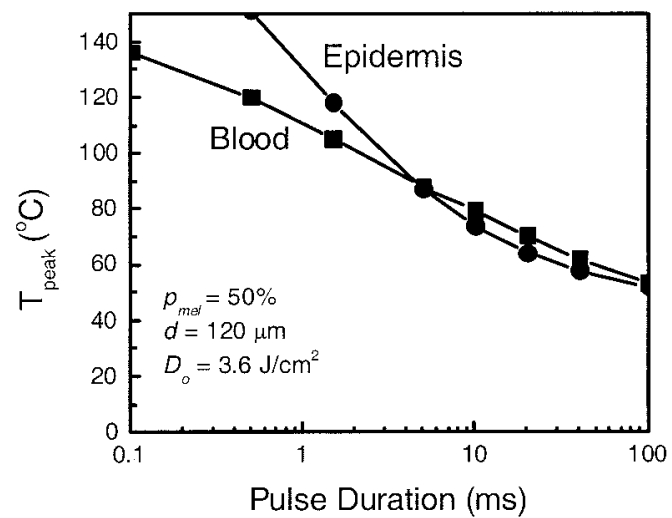

Fig. 6. Peak temperature $T_{\text {peak }}$ generated within the blood vessel and epidermis versus pulse duration $t_{p}$ for a constant radiant exposure. 


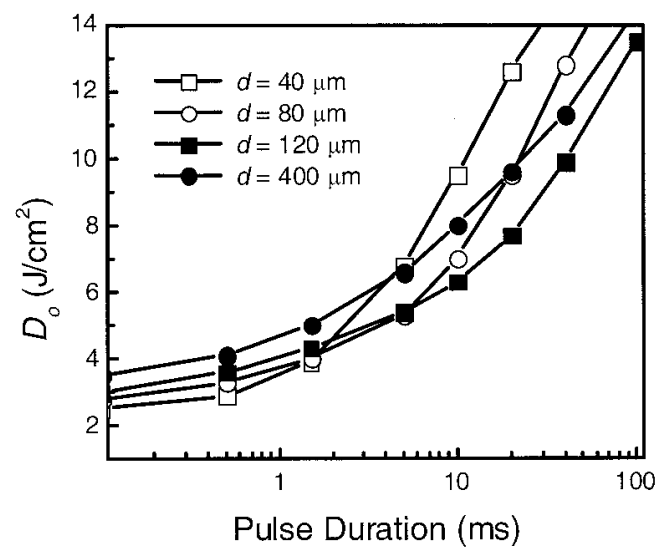

Fig. 7. Therapeutic radiant exposure $D_{o}$ versus laser pulse duration $t_{p}$ for each of the vessel sizes in this study.

the slope transition in $D_{o}$ occurs in Fig. 7 and increases with vessel size (Fig. 8).

Although increasing the pulse duration decreases the epidermal $T_{\text {peak }}$, none of the temperatures in Fig. 8 fall below the threshold level for thermal injury to the epidermis. Use of CSC can decrease the epidermal temperature below the threshold level (dashed curve, Fig. 9). Figure 9 shows the epidermal $T_{\text {peak }}$ for $120-\mu \mathrm{m}$-sized vessels without and with a $100-\mathrm{ms}$ cryogen spurt. For short pulse durations, CSC alone is not sufficient to reduce the epidermal $T_{\text {peak }}$ below the damage threshold. In addition, use of the optimum $t_{p}(=20 \mathrm{~ms})$ without CSC is not sufficient to reduce the epidermal $T_{\text {peak }}$ below the epidermal damage threshold; however, the addition of both CSC and optimum $t_{p}$ reduces the epidermal $T_{\text {peak }}$ below the damage threshold.

We illustrate the combination of increased pulse duration and CSC to achieve a therapeutic response in dark skin while protecting the epidermis. Figure 10 shows temperature and damage map profiles in dark skin with $d=120 \mu \mathrm{m}$ : (a), (b) $D_{o}$ for $t_{p}=0.5$ $\mathrm{ms}$ and $t_{\mathrm{CSC}}=0 \mathrm{~ms}$; (c), (d) $D_{o}$ for $t_{p}=0.5 \mathrm{~ms}$ and

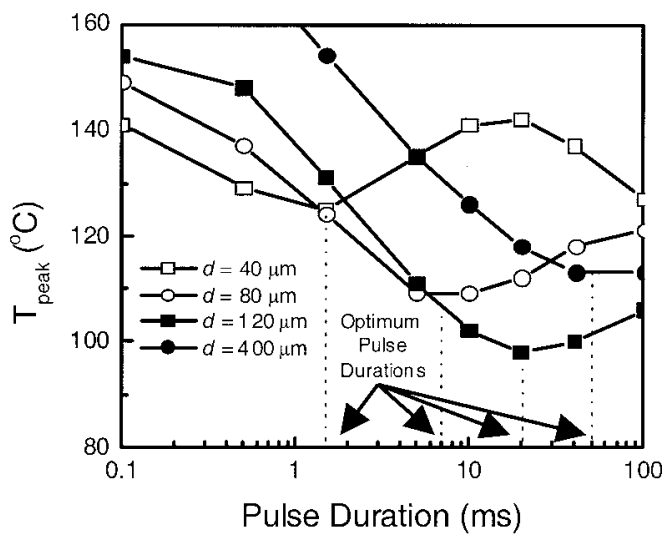

Fig. 8. Peak temperature $T_{\text {peak }}$ within the epidermis immediately at the end of the laser pulse when the skin is irradiated at the therapeutic radiant exposure $D_{o}$ versus laser pulse duration $\left(t_{p}\right)$ for each vessel size in this study.

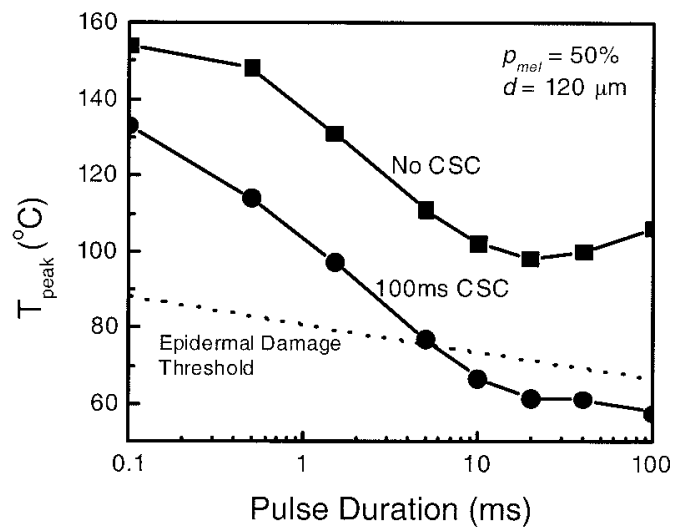

Fig. 9. Peak temperature $T_{\text {peak }}$ within the epidermis immediately at the end of the laser pulse when the skin is irradiated at the therapeutic radiant exposure $D_{o}$ versus laser pulse duration $t_{p}$ for $d=120 \mu \mathrm{m}$ without and with $\operatorname{CSC}\left(t_{\mathrm{CSC}}=100 \mathrm{~ms}\right)$. Dashed curve, threshold temperature for epidermal damage $\left(T_{\text {th }}\right)$.

$t_{\mathrm{CSC}}=100 \mathrm{~ms}$; (e), (f) $D_{o}$ for $t_{p}=20 \mathrm{~ms}$ and $t_{\mathrm{CSC}}=0$ $\mathrm{ms}$; and (g), (h) $D_{o}$ for $t_{p}=20 \mathrm{~ms}$ and $t_{\mathrm{CSC}}=100 \mathrm{~ms}$.

\section{Discussion}

A. Influence of Cryogen Spray Cooling and Pigmentation on Epidermal Injury

Figure 3 illustrates the relationship among epidermal damage threshold, epidermal pigmentation, and duration of cryogen spurt. The epidermal damage threshold decreases with epidermal pigmentation and increases with duration of cryogen spurt, so the use of CSC allows for higher radiant exposures while it preserves the epidermis.

Values of $D_{o}$ increase with $p_{\text {mel }}$ because absorption of light by melanin within the overlying epidermis limits fluence within the dermis; therefore, higher radiant exposures are needed to raise the blood temperature. Light skin $\left(p_{\text {mel }}=5 \%\right)$ is not interesting with respect to cooling because epidermal injury did not occur even without cooling (i.e., $D_{\text {th }}$ exceeded $D_{o}$ for all $t_{\mathrm{CSC}}$ in Fig. 3). In addition, dark epidermis could not be protected at $t_{p}=1.5 \mathrm{~ms}$, even at the longest spurt durations (i.e., $D_{\text {th }}$ never exceeded $D_{o}$ for $p_{\text {mel }}=50 \%$ in Fig. 3). However, moderately pigmented skin $\left(p_{\text {mel }}=25 \%\right)$ provided a good example of the ability of CSC to increase the selectivity of vascular injury. Figure 3 shows that epidermal injury occurs for moderately pigmented skin with no cooling (i.e., $D_{o}$ exceeds $D_{\text {th }}$ for $t_{\mathrm{CSC}}=0$ ) but does not occur for spurt durations greater than $50 \mathrm{~ms}$. This result suggests that during a therapeutic procedure in which $t_{p}=1.5 \mathrm{~ms}, \mathrm{CSC}$ can be used to avoid epidermal injury in moderately pigmented skin but not in darkly pigmented skin.

The depth profile view of Fig. 4 illustrates how superficial blood vessels are at a much higher temperature than vessels deeper within the dermis. The long cooling duration $\left(t_{\mathrm{CSC}}=300 \mathrm{~ms}\right)$ decreased the blood temperatures near the skin surface, so blood vessel heating was more nearly even as the 


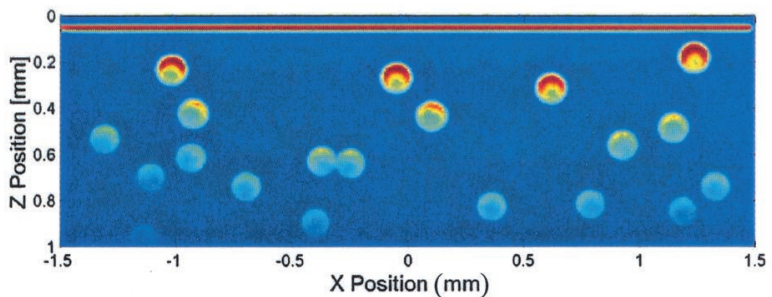

(a)

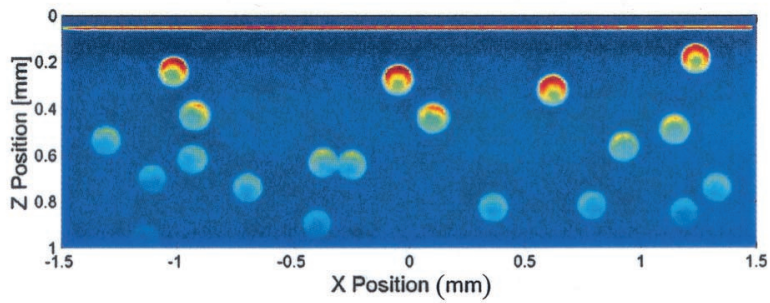

(c)

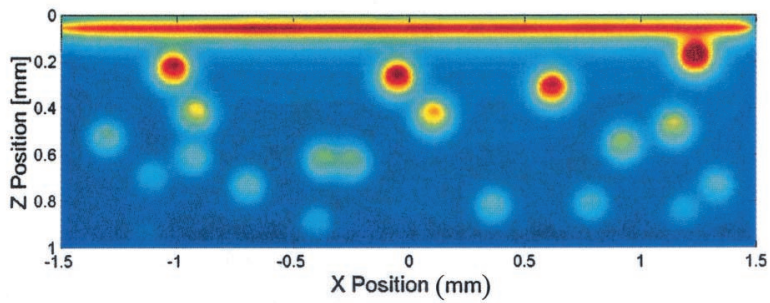

(e)

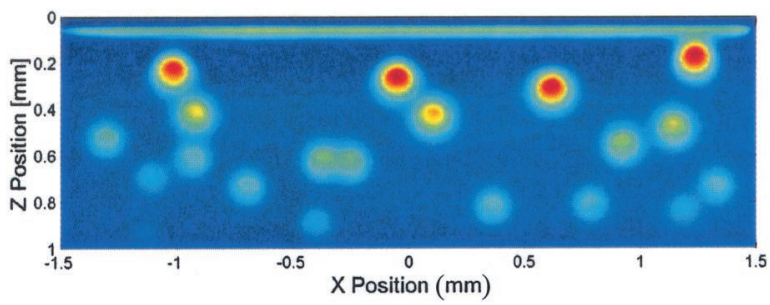

(g)

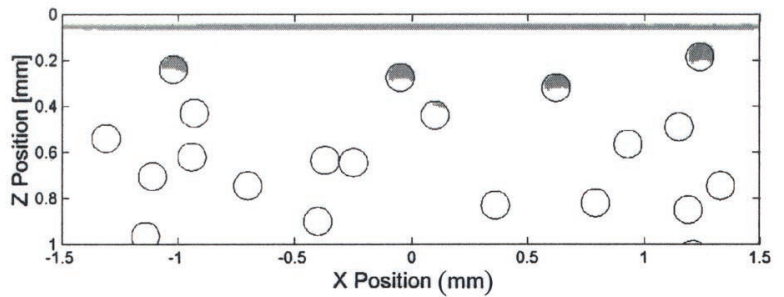

(b)

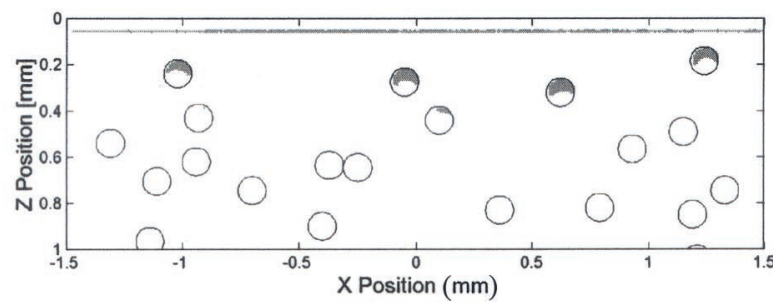

(d)

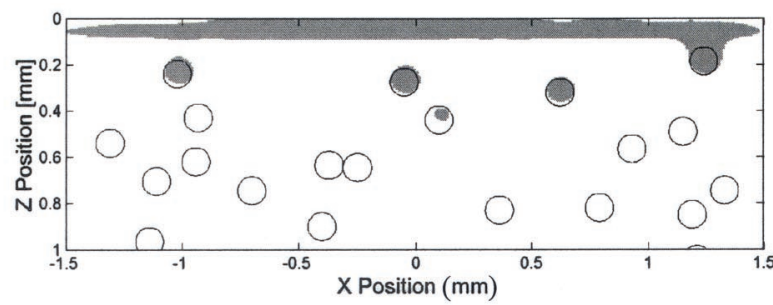

(f)

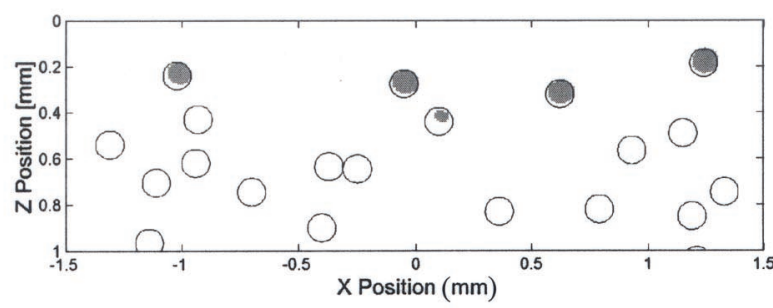

(h)

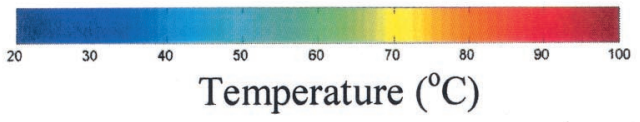

Fig. 10. False color temperature and skin damage maps for $d=120 \mu \mathrm{m}$ and $p_{\text {mel }}=50 \%$. Four cases are shown: (a), (b) $D=D_{o}$ for $t_{p}=0.5 \mathrm{~ms}, t_{\mathrm{CSC}}=0 \mathrm{~ms}$; (c), (d) $D=D_{o}$ for $t_{p}=0.5 \mathrm{~ms}, t_{\mathrm{CSC}}=100 \mathrm{~ms}$; (e), (f) $D=D_{o}$ for $t_{p}=20 \mathrm{~ms}, t_{\mathrm{CSC}}=0 \mathrm{~ms}$; and (g), (h) $D=D_{o}$ for $t_{p}=20 \mathrm{~ms}, t_{\mathrm{CSC}}=100 \mathrm{~ms}$.

depth increased. At $5 \mathrm{~ms}$ after the laser pulse [Figs. 4(c) and 4(d)] the maximum blood temperature was below $80{ }^{\circ} \mathrm{C}$ in the cooled case [Fig. 4(d)], whereas in the noncooled case [Fig. 4(c)] it was still well above $100{ }^{\circ} \mathrm{C}$. At $10 \mathrm{~ms}$ following the laser pulse [Figs. 4(e) and $4(\mathrm{f})$ ], blood temperatures within the noncooled case [Fig. 4(e)] were just approaching $80^{\circ} \mathrm{C}$. The spatial heating profiles within the cooled cases [Figs. 4(b), 4(d), and 4(f)] were much flatter than in the noncooled cases [Figs. 4(a), 4(c), and 4(e)]. These results illustrate the ability of CSC to alter the initial skin temperature profile in such a way as to achieve a more nearly even heating distribution with depth.

Our results of modeling threshold radiant exposures for epidermal injury over various skin pigmentations are in good agreement with recent 
experimental studies. A study of high radiant exposures in conjunction with CSC of ex vivo human skin showed that cryogen spurt durations of $250 \mathrm{~ms}$ were required for doubling the epidermal damage threshold from 15 to $30 \mathrm{~J} / \mathrm{cm}^{2}$ in lightly pigmented Caucasian skin. ${ }^{10}$ An in vivo study investigating high radiant exposures in conjunction with CSC showed that cryogen spurt durations greater than $200 \mathrm{~ms}$ were needed to increase the epidermal damage threshold from 23 to $30 \mathrm{~J} / \mathrm{cm}^{2}$ in lightly pigmented skin and from 16 to $30 \mathrm{~J} / \mathrm{cm}^{2}$ in moderately pigmented skin; however, darkly pigmented skin was not protected at the lowest radiant exposure tested in that study $\left(8 \mathrm{~J} / \mathrm{cm}^{2}\right)$, even with cryogen spurt durations of $300 \mathrm{~ms}^{5}$ In that study, little to no blood vessel injury was observed at $8 \mathrm{~J} / \mathrm{cm}^{2}$, indicating that the threshold radiant exposures for a therapeutic outcome $\left(D_{o}\right)$ had not been reached. Our model shows that, in all skin pigmentation levels, threshold radiant exposures for epidermal damage can be increased by approximately a factor of 2 when CSC is used (Fig. 3). For lightly to moderately pigmented skin, CSC can be used to increase the threshold radiant exposure for epidermal damage significantly above $D_{o}$; however, the threshold radiant exposure for epidermal damage cannot be increased above $D_{o}$ in dark skin with CSC at short pulse durations.

The model also predicts that high radiant exposures can lead to perivascular tissue damage (Fig. 5). This type of injury was observed in vivo in human skin $^{5}$ irradiated at high radiant exposures. Diffuse coagulation of dermal collagen surrounding the vasculature was observed when high radiant exposures were used without CSC; however, the use of cryogen spurts longer than $200 \mathrm{~ms}$ eliminated this type of nonselective thermal injury. From the model we observed that the longer cryogen spurts allowed for cooling not only of the epidermis but also of the superficial blood vessels. Altering the initial skin temperature profile with CSC can prevent excessive heating of the superficial blood vessels. This finding contrasts with the previous belief that no cooling of the blood vessels should occur. We propose that some cooling of the blood vessels can be effective in eliminating perivascular damage, especially when increased radiant exposures are used.

A twofold increase in the radiant exposure increase the temperature within the vessels substantially. For $80-\mu \mathrm{m}$-diameter vessels the maximum temperatures within blood are predicted to increase from $120{ }^{\circ} \mathrm{C}$ to greater than $200^{\circ} \mathrm{C}$ without the use of $\mathrm{CSC}$ and to just above $160{ }^{\circ} \mathrm{C}$ with $t_{\mathrm{CSC}}=300 \mathrm{~ms}$ (Fig. 4). However, these high temperatures are not likely to occur within the skin, as energy would be lost to induce phase changes during water vaporization and photomechanical effects. Our model has not taken those forms of energy transfer into account.

We utilized a thermal boundary condition simulating CSC that was consistent with previous reports of cryogen spray cooling of skin. ${ }^{39,40,42,44}$ We represented the thermal boundary condition as a timevarying heat flux in three time intervals: during the application of the cryogen spurt, during the time when the cryogen pool lay on the surface of the skin, and after complete cryogen evaporation. The cryogen was sprayed onto the skin surface continuously during the spurt duration, $t_{\mathrm{CSC}}$. A cryogen pool developed on the skin surface during the duration of the spurt and remained thereon for a time interval several times longer than the duration of the cryogen spurt itself before it evaporated. The laser pulse is most often delivered immediately following the end of the cryogen spurt. Several recent reports ${ }^{40}$ quantified $h_{1}$ to be $2400-8400\left(\mathrm{~W} / \mathrm{m}^{2}{ }^{\circ} \mathrm{C}\right),{ }^{30,42}$ depending on the experimental conditions such as the type of the cryogen delivery device and the spraying distance. We chose a reasonably conservative value of $h_{1}$ $=4000\left(\mathrm{~W} / \mathrm{m}^{2}{ }^{\circ} \mathrm{C}\right)$ during the first time interval. Tunnell et al. ${ }^{39}$ estimated $h_{2}$ to be approximately $75 \%$ of $h_{1}$. Therefore we chose $h_{2}=3000\left(\mathrm{~W} / \mathrm{m}^{2}{ }^{\circ} \mathrm{C}\right)$ for this study. The value of $h_{3}$ was chosen to represent that of a light air flow over a flat surface $\left(\sim 10 \mathrm{~W} / \mathrm{m}^{2}{ }^{\circ} \mathrm{C}\right) .45$ The value of $T_{1}$ ranges from approximately -40 to $-60{ }^{\circ} \mathrm{C}$ and depends strongly on the cryogen-nozzle-to-skin distance. ${ }^{42,46}$ The value of $T_{2}$ has been measured to be approximately equal to the boiling point of the cryogen at 1 atm (i.e., $\left.-26{ }^{\circ} \mathrm{C}\right) .22,39,40$ Values of $T_{3}$ correspond to the ambient air temperature of $25^{\circ} \mathrm{C}$. This thermal boundary condition is the determinant of the epidermal temperature profile that is due to CSC and thus directly affects epidermal injury.

\section{B. Pulse Duration and Epidermal Injury}

Because previous experimental studies ${ }^{5}$ indicated that CSC alone is not successful in protecting the dark-skinned epidermis, in this study we investigated the effect of pulse duration on epidermal injury. The peak temperatures within the epidermis and blood vessels decrease with increasing pulse durations for irradiation at constant radiant exposures (Fig. 6). The decrease in temperature of these structures is due to thermal diffusion during the laser pulse.

The radiant exposure must be increased to maintain a therapeutic effect within the blood vessels (Fig. 7). At short pulse durations, thermal diffusion is negligible and $D_{o}$ increases only slightly with $t_{p}$. However, as $t_{p}$ increases, heat loss caused by thermal diffusion becomes substantial, and $D_{o}$ increases rapidly with $t_{p}$. That is, the radiant exposure needed to induce a therapeutic temperature within the blood increases rapidly with pulse duration. In addition, the pulse duration of the slope transition $\left(t_{p}{ }^{\prime}\right)$ from relatively flat at short pulse durations to steep at long pulse durations increases with blood vessel size, so, when one is targeting larger-diameter vessels, a longer pulse duration can be used with little increase in radiant exposure.

At pulse durations less than $t_{p}{ }^{\prime}$, skin temperature is governed by the light-distribution profile, and $D_{o}$ increases with vessel size. For the smaller vessel sizes studied here, a lower blood volume fraction was present within the dermis. For example, the geom- 
etry containing $40-\mu \mathrm{m}$ vessels had a blood volume fraction of $3.2 \%$, whereas the geometry containing $80-\mu \mathrm{m}$ vessels had a blood volume fraction of $6 \%$. Given the same radiant exposure (i.e., the same number of photons), the skin with the smaller vessel size would have a higher number of photons absorbed per unit volume within the blood, leading to higher $S(x$, $z)$. Given that heat loss from the vessel at short pulse durations was low, $D_{o}$ would be lower in lesions with smaller vessels and lower blood volume than those with larger vessels and higher blood volume (Fig. 7).

At pulse durations greater than $t_{p}{ }^{\prime}$ the skin temperature is governed by both the light-distribution profile and thermal diffusion. Thus, at longer pulse durations $(>5 \mathrm{~ms}) D_{o}$ decreases with vessel size. This implies that thermal damage to smaller vessels is spared when larger vessels with longer pulse durations are targeted, because $D_{o}$ has not been achieved for the smaller vessel size.

The peak temperature within the epidermis depends on the radiant exposure and the laser pulse duration. To induce a therapeutic effect within the blood we had to use the therapeutic radiant exposures in Fig. 7. The peak temperature within the epidermis associated with the therapeutic radiant exposures of Fig. 7 is shown in Fig. 8 for the respective blood vessel size and laser pulse duration. We define the optimum pulse duration during which the peak epidermal temperature reaches a minimum. This pulse duration increases with blood vessel size. For example, the optimum pulse durations occurred at $t_{p}{ }^{\prime} \cong 1.5,6,20,50 \mathrm{~ms}$ for blood vessel diameters of $40,80,120$, and $400 \mu \mathrm{m}$, respectively. Enlarged blood vessel diameters within port-wine stain birthmarks range from approximately 50 to $120 \mu \mathrm{m}$, with an average of $70 \mu \mathrm{m} .{ }^{24}$ Vessel diameters within leg veins and telangiectasia can be much larger $(>400$ $\mu \mathrm{m})$.

Although increasing the pulse duration decreased the epidermal temperature more than $50{ }^{\circ} \mathrm{C}$ in the simulated dark skin, the epidermal temperature was still not below that of the damage threshold. However, the combination of increased pulse duration and CSC showed that the temperature of the epidermis may be decreased below the damage threshold (Fig. 9). Figure 10 further illustrates this point by showing temperature and damage maps of dark skin irradiated at several pulse durations with and without CSC. When a short pulse duration is used, there is minimal thermal diffusion into the dermal perivascular tissue; however, the epidermis is not protected even when CSC is used [Figs. 10(a)-10(d)]. The use of a longer pulse duration without CSC results in extensive epidermal damage, as shown in Fig. 10(f). A diffuse hot layer is seen within the epidermis, as much of the heat generated within the basal layer diffuses upward [Fig. 10(e)]. With CSC, epidermal temperatures are drastically decreased and injury to the epidermis is eliminated when a longer pulse is used [Figs. 10(g) and 10(h)]. In addition, significant thermal injury is predicted within the blood vessels.
Therefore, by use of appropriate pulse duration and CSC it may be possible to treat patients who otherwise may have been untreatable.

Currently, the pulsed dye laser at $585 \mathrm{~nm}$ is widely considered the treatment device of choice. The longest pulse duration of currently available pulsed dye lasers at $585 \mathrm{~nm}$ is $1.5 \mathrm{~ms}$, and the technology to create longer pulse durations at $585 \mathrm{~nm}$ currently does not exist. Several dye lasers on the market deliver a train of shorter pulses (of the order of hundreds of microseconds) that add up to as long as 40 ms. It is not yet clear whether these pulse trains successfully approximate longer pulse durations. ${ }^{47}$ Perhaps other laser wavelengths for treatment of darker-skinned patients should be explored where the technology for using longer pulse durations exists. For example, the frequency-doubled Nd:YAG laser at $532 \mathrm{~nm}$ can deliver longer pulse durations than the pulsed dye laser. A preliminary study ${ }^{48}$ that used 532-nm irradiation at $10-\mathrm{ms}$ pulse duration has shown that CSC can substantially reduce epidermal temperatures and allow for use of higher radiant exposures in patients with port-wine stain birthmarks. It may be that other laser technologies that allow for longer pulse durations will be the treatment devices of choice for darker-skinned individuals.

Because of the theoretical nature of this research, the exact radiant exposures, pulse durations, and spurt durations may differ from clinical values. The model serves to show the trends that would be expected during therapeutic sessions. Experimental studies will be required for determining the optimum pulse duration and incident fluence for a given skin type. Nevertheless, our modeling results show that longer pulse durations can decrease epidermal injury when they are combined with CSC. Future experiments will focus on proving this concept. We are currently carrying out experiments to investigate the effects of longer pulse durations in conjunction with CSC.

\section{Conclusion}

This study indicates that increased radiant exposures in conjunction with CSC can improve the clinical outcome in laser treatment of cutaneous hypervascular malformations. CSC can decrease damage to perivascular tissue as well as to epidermal tissue; however, the cryogen spurt durations necessary to maintain selective vascular injury when increased radiant exposure is used need to be greater than those currently used in the clinic, which are in the range of 30-60 ms.

Although CSC can increase the epidermal damage threshold, this study shows that it is not sufficient to protect the epidermis in dark-skinned patients. There exists an optimum pulse duration at which the epidermal injury is minimal while coagulation of dermal blood vessels still occurs. The use of this optimum pulse duration in combination with CSC may provide a means to treat dark-skinned patients. 
This study was supported in part by grants to B. Anvari from the Institute of Arthritis and Musculoskeletal and Skin Disease of the National Institutes of Health (1R01-AR47996) and from the Texas Higher Education Board.

\section{References}

1. R. R. Anderson and J. A. Parrish, "Selective photothermolysis: precise microsurgery by selective absorption of pulsed radiation," Science 220, 524-527 (1983).

2. W. S. Ho, H. H. Chan, S. Y. Ying, and P. C. Chan, "Laser treatment of congenital facial port-wine stains: long-term efficacy and complication in Chinese patients," Lasers Surg. Med. 30, 44-47 (2002).

3. U. Wlotzke, U. Hohenleutner, T. A. Abd-El-Raheem, W. Baumler, and M. Landthaler, "Side-effects and complications of flashlamp-pumped pulsed dye laser therapy of port-wine stains. A prospective study," Br. J. Dermatol. 134, 475-480 (1996).

4. B. A. Reyes and R. Geronemus, "Treatment of port-wine stains during childhood with the flashlamp-pumped pulsed dye laser," J. Am. Acad. Dermatol. 23, 1142-1148 (1990).

5. J. W. Tunnell, D. W. Chang, C. Johnston, J. H. Torres, C. W. Patrick, M. J. Miller, S. L. Thomsen, and B. Anvari, "In vivo study of epidermal protection by cryogen spray cooling during pulsed laser irradiation at high radiant exposures," in Lasers in Surgery: Advanced Characterization, Therapeutics, and Systems XII, L. S. Bass and N. Kollias, eds., Proc. SPIE 4609, 67-74 (2002).

6. J. S. Nelson, T. E. Milner, B. Anvari, B. S. Tanenbaum, L. O. Svaasand, and S. Kimel, "Dynamic epidermal cooling in conjunction with laser-induced photothermolysis of port wine stain blood vessels," Lasers Surg. Med. 19, 224-229 (1996).

7. C. J. Chang and J. S. Nelson, "Cryogen spray cooling and higher fluence pulsed dye laser treatment improve port-wine stain clearance while minimizing epidermal damage," Dermatol. Surg. 25, 767-772 (1999).

8. K. M. Kelly, V. S. Nanda, and J. S. Nelson, "Treatment of port-wine stain birthmarks using the 1.5-msec pulsed dye laser at high fluences in conjunction with cryogen spray cooling," Dermatol. Surg. 28, 309-313 (2002).

9. B. Anvari, T. E. Milner, B. S. Tanenbaum, S. Kimel, L. O. Svaasand, and J. S. Nelson, "Dynamic epidermal cooling in conjunction with laser treatment of port-wine stains: theoretical and preliminary clinical evaluations," Lasers Med. Sci. 10, 105-112 (1995).

10. J. W. Tunnell, J. S. Nelson, J. H. Torres, and B. Anvari, "Epidermal protection with cryogen spray cooling during high fluence pulsed dye laser irradiation: an ex vivo study," Lasers Surg. Med. 27, 373-383 (2000).

11. W. Verkruysse, B. Majaron, B. S. Tanenbaum, and J. S. Nelson, "Optimal cryogen spray cooling parameters for pulsed laser treatment of port wine stains," Lasers Surg. Med. 27, 165-170 (2000).

12. I. D. Miller and A. R. Veitch, "Optical modelling of light distributions in skin tissue following laser irradiation," Lasers Surg. Med. 13, 565-571 (1993).

13. E. V. Ross and D. Paithankar, "Comparison of cryogen spray and surface contact cooling through heat transfer modeling," Laser News 1 (2000), http://www.lasernews.net.

14. T. J. Pfefer, D. J. Smithies, T. E. Milner, M. J. van Gemert, J. S. Nelson, and A. J. Welch, "Bioheat transfer analysis of cryogen spray cooling during laser treatment of port wine stains," Lasers Surg. Med. 26, 145-157 (2000).

15. B. Anvari, B. S. Tanenbaum, T. E. Milner, S. Kimel, L. O. Svaasand, and J. S. Nelson, "A theoretical study of the thermal response of skin to cryogen spray cooling and pulsed laser irradiation: implications for treatment of port wine stain birthmarks," Phys. Med. Biol. 40, 1451-1465 (1995).

16. M. J. van Gemert, D. J. Smithies, W. Verkruysse, T. E. Milner, and J. S. Nelson, "Wavelengths for port wine stain laser treatment: influence of vessel radius and skin anatomy," Phys. Med. Biol. 42, 41-50 (1997).

17. W. Verkruysse, J. W. Pickering, J. F. Beek, M. Keijzer, and M. J. van Gemert, "Modeling the effect of wavelength on the pulsed dye laser treatment of port wine stains," Appl. Opt. 32, 393-398 (1993).

18. M. J. van Gemert, S. L. Jacques, H. J. Sterenborg, and W. M. Star, "Skin optics," IEEE Trans. Biomed. Eng. 36, 1146-1154 (1989).

19. G. W. Lucassen, W. Verkruysse, M. Keijzer, and M. J. van Gemert, "Light distributions in a port wine stain model containing multiple cylindrical and curved blood vessels," Lasers Surg. Med. 18, 345-357 (1996).

20. C. Sturesson and S. Andersson-Engels, "Mathematical modelling of dynamic cooling and pre-heating, used to increase the depth of selective damage to blood vessels in laser treatment of port wine stains," Phys. Med. Biol. 41, 413-428 (1996).

21. M. K. Loze and C. D. Wright, "Temperature distributions in laser-heated biological tissue with application to birthmark removal," J. Biomed. Opt. 6, 74-85 (2001).

22. J. H. Torres, J. W. Tunnell, B. M. Pikkula, and B. Anvari, "An analysis of heat removal during cryogen spray cooling and effects of simultaneous airflow application," Lasers Surg. Med. 28, 477-486 (2001).

23. J. Pearce and S. L. Thomsen, "Rate process analysis of thermal damage," in Optical-Thermal Response of Laser Irradiated Tissue, A. J. Welch and M. J. van Gemert, eds. (Plenum, New York, 1995), pp. 561-606.

24. S. H. Barsky, S. Rosen, D. E. Geer, and J. M. Noe, "The nature and evolution of port wine stains: a computer-assisted study," J. Invest Dermatol. 74, 154-157 (1980).

25. J. L. Finley, S. H. Barsky, D. E. Geer, B. R. Kamat, J. M. Noe, and S. Rosen, "Healing of port-wine stains after argon laser therapy," Arch. Dermatol. 117, 486-489 (1981).

26. L. Wang, S. L. Jacques, and L. Zheng, "MCML-Monte Carlo modeling of light transport in multi-layered tissues," Comput. Methods Programs Biomed. 47, 131-146 (1995).

27. L. V. Wang and G. Liang, "Absorption distribution of an optical beam focused into a turbid medium," Appl. Opt. 38, 4951-4958 (1999).

28. L. V. Wang, R. E. Nordquist, and W. R. Chen, "Optimal beam size for light delivery to absorption-enhanced tumors buried in biological tissues and effect of multiple-beam enhanced delivery: a Monte Carlo study," Appl. Opt. 36, 8286-8291 (1997).

29. B. C. Wilson and G. Adam, "A Monte Carlo model for the absorption and flux distributions of light in tissue," Med. Phys. 10, 824-830 (1983).

30. M. J. van Gemert, A. J. Welch, J. W. Pickering, and O. T. Tan, "Laser treatment of port-wine stains," in Optical-Thermal Response of Laser Irradiated Tissue, A. J. Welch and M. J. van Gemert, eds. (Plenum, New York, 1995), pp. 789-830.

31. J. Bhawan, A. Gonzalez-Serva, K. Nehal, R. Labadie, L. Lufrano, E. G. Thorne, and B. A. Gilchrest, "Effects of tretinoin on photodamaged skin. A histologic study," Arch. Dermatol. 127, 666-672 (1991).

32. J. Bhawan, W. Andersen, J. Lee, R. Labadie, and G. Solares, "Photoaging versus intrinsic aging: a morphologic assessment of facial skin," J. Cutan. Pathol. 22, 154-159 (1995).

33. E. S. Lee, J. H. Kim, S. Im, K. B. Lee, S. Sohn, and W. H. Kang, "Application of computerized image analysis in pigmentary skin diseases," Int. J. Dermatol. 40, 45-49 (2001).

34. W. K. Andersen, R. R. Labadie, and J. Bhawan, "Histopathology of solar lentigines of the face: a quantitative study," J. Am. Acad. Dermatol. 36, 444-447 (1997). 
35. H. Lu, C. Edwards, S. Gaskell, A. Pearse, and R. Marks, "Melanin content and distribution in the surface corneocyte with skin phototypes,” Br. J. Dermatol. 135, 263-267 (1996).

36. M. N. Ozisik, Heat Conduction (Wiley, New York, 1993).

37. A. J. Welch, E. H. Wissler, and L. A. Priebe, "Significance of blood flow in calculations of temperature in laser irradiated tissue," IEEE Trans. Biomed. Eng. 27, 164-166 (1980).

38. F. A. Duck, Physical Properties of Tissue. A Comprehensive Reference Book (Academic, London, 1990).

39. J. W. Tunnell, J. H. Torres, and B. Anvari, "Methodology for estimation of time-dependent surface heat flux due to cryogen spray cooling," Ann. Biomed. Eng. 30, 19-33 (2002).

40. J. H. Torres, J. S. Nelson, B. S. Tanenbaum, T. Milner, D. M. Goodman, and B. Anvari, "Estimation of internal skin temperatures in response to cryogen spray cooling: implications for laser therapy of port wine stains," IEEE J. Sel. Top. Quantum Electron. 5, 1058-1066 (1999).

41. B. Majaron, S. Kimel, W. Verkruysse, G. Aguilar, K. Pope, L. O. Svaasand, E. J. Lavernia, and J. S. Nelson, "Cryogen spray cooling in laser dermatology: effects of ambient humidity and frost formation," Lasers Surg. Med. 28, 469-476 (2001).

42. G. Aguilar, B. Majaron, K. Pope, L. O. Svaasand, E. J. Lavernia, and J. S. Nelson, "Influence of nozzle-to-skin distance in cryogen spray cooling for dermatologic laser surgery," Lasers Surg. Med. 28, 113-120 (2001).

43. J. A. Weaver and A. M. Stoll, "Mathematical model of skin exposed to thermal radiation," Aerosp. Med. 40, 24-30 (1969).

44. W. Verkruysse, B. Majaron, G. Aguilar, L. O. Svaasand, and J. S. Nelson, "Dynamics of cryogen spray deposition relative to heat extraction rate during cryogen spray cooling," in Lasers in Surgery: Advanced Characterization, Therapeutics, and Systems $X$, R. R. Anderson, K. Bartels, and L. S. Bass, eds., Proc. SPIE 3907, 37-48 (2000).

45. J. P. Holman, Heat Transfer (McGraw-Hill, New York, 1981).

46. B. M. Pikkula, J. H. Torres, J. W. Tunnell, and B. Anvari, "Cryogen spray cooling: effects of droplet size and spray density on heat removal," Lasers Surg. Med. 28, 103-112 (2001).

47. S. Kimel, L. O. Svaasand, D. Cao, M. J. Hammer-Wilson, and J. S. Nelson, "Vascular response to laser photothermolysis as a function of pulse duration, vessel type, and diameter: implications for port wine stain laser therapy," Lasers Surg. Med. 30, 160-169 (2002).

48. B. Anvari, B. V. Steeg, B. S. Tanenbaum, and J. S. Nelson, "Cryogen spray cooling: a preliminary study during $532 \mathrm{~nm}$ laser irradiation of port wine stains," Cosmet. Dermatol. 13, 22-26 (2000). 